\title{
INFLUENCE OF INNOVATIVE HEALTH-SAVING EDUCATION TECHNOLOGIES ON IMPROVEMENT OF MENTAL ACTIVITY OF STUDENTS
}

\author{
Zhannat Saparkyzy ${ }^{1, *}$, Sharbanu Maygeldiyeva ${ }^{1}, Z^{2}$ nnat Maygeldiyeva ${ }^{1}$, Sagat Taiman ${ }^{1}$, \\ Sandigul Daribaeva ${ }^{1}$ \\ ${ }^{1}$ Korkyt Ata Kyzylorda State University, 29A, Aiteke bi str., 120014 Kyzylorda, Kazakhstan
}

\begin{abstract}
The authors of the article note that in recent years, numerous attempts have been made to develop and implement health-saving technologies and methods of health improvement, programs of valeological education of students. However, as scientific analysis and actual practice shows, it is not yet possible to get the desired results. This article deals with the problem of exceptional importance in terms of finding psychological and pedagogical influence and ways to introduce innovative technologies for the development and improvement of mental activity, which contribute not only to the optimal achievement of educational goals and provide a full solution of educational tasks, but also contribute to the preservation and strengthening of the health of the subjects of the integral pedagogical process. The authors presented a scientific justification for the criteria and indicators for improving the mental activity of students based on the use of health-saving learning technologies and the content of the structural component model developed by them. The results of a questionnaire conducted among students and teachers are presented. The article concludes that the following types of pedagogical activities are necessary within the framework of the ongoing process: diagnostic, didactic, preventive, Advisory, corrective and health-improving procedures through the organization of a system of classes with the use of health-saving technologies - exercises for eyes, herbal medicine, aromatherapy, etc.
\end{abstract}

\section{INTRODUCTION}

In the context of the modern practice of university education, which is characterized by a high volume and intensity of the educational process, various innovations, the problem of maintaining and strengthening health, and introducing students to a healthy lifestyle, becomes extremely important. Since the development of many innovations that are currently

*Corresponding author: 793@mail.ru 
being included in the content of education requires considerable energy costs from participants in the educational process, and therefore their education is "paid for" at a high price - at the cost of their health. Recognizing the importance and necessity of creating a healthy lifestyle, the Government of the Republic of Kazakhstan reflected this problem in a number of documents: "Development Strategy of the Republic of Kazakhstan until 2050" [1], "Healthy Kazakhstan" [2], Law of the Republic of Kazakhstan "On the Protection of Citizens' Health" [3] predicting and determining the main ways of preserving and strengthening the health of Kazakhstani citizens, including students.

The issues of raising a healthy lifestyle have always been the focus of attention of educators. In recent years, numerous attempts have been made to develop and put into practice health-saving technologies and methods of rehabilitation, and programs for the valeological education of students. However, as shown by scientific analysis and real practice, it is not possible to obtain the desired results yet. In the article, we tried to show the results of our study to determine the psychological and pedagogical impact of innovative health-saving teaching technologies on the development and improvement of students' mental activity.

Higher education has a huge impact on the human psyche, the development of his or her personality. During the training at the university having favorable conditions, students develop all levels of the psyche. They determine the direction of the human mind, i.e. form a mindset that characterizes the professional orientation of the personality. For successful study at a university a rather high level of general intellectual development is necessary, in particular, perception, memory, thinking, attention, erudition, breadth of cognitive interests and level of knowledge of a certain range of logical operations. With a slight decrease in this level, compensation is possible due to increased motivation and efficiency, perseverance, thoroughness and accuracy in educational activities.

Taking into account that the most important condition for ensuring the health of a student is the success of his educational activity, we state that it is a successful educational activity that contributes to the formation of a favorable psychological microclimate and his wellbeing in an educational institution, which ultimately provides for each of them the opportunity to develop and improve according to their individual features.

In connection with the foregoing, a change in the general paradigm is relevant: the transition from a narrow orientation only to maintaining and strengthening health, to a wider implementation of innovative technologies that provide for the formation of skills, attitudes and relationships necessary for awareness and assessment of one's own health, motivating a healthy lifestyle, the adoption of its values and contributing to the development of adequate behavior of a healthy person.

Hence the problem of the exceptional importance of seeking psychological and pedagogical influence and ways of introducing innovative technologies for the development and improvement of mental activity occur. As it is known the educational activity of students is their leading activity. To increase the level of educational activity, it is necessary to form mental activity among students, strengthen learning motivation and use traditional and new technologies, modern information technologies, including health-saving technologies.

To date, a sufficient amount of knowledge has been accumulated in pedagogical science necessary for the formulation and solution of the problem under study $[4 ; 5 ; 6 ; 7]$.

Questions of the development of philosophical, pedagogical, medical ideas about the value of health and ways to preserve it, as well as certain aspects of the problem of creating health care and maintaining a healthy lifestyle (HLS) of holistic pedagogical process subjects, were covered in foreign works (R.I.Aizman, E.N. Weiner, O.L. Trescheva, V.V. Popov, B.N. Chumakov, L.G. Tatarnikova, I.V. Yakovlev, E.R. Margiev, P.L. Dribinsky, R.N. Denisenko, P.P. Thyssen, R.V. Rozhnov, V.N. Priz, V.F. Neretin, M.E. Kosheleva, N.P. Abaskalov, L.I. Ponomarev, A.S. Wulfovich) and the domestic scientists (A.S. Imangaliev, 
G.D. Alimzhanova, A.V. Ahaev, L.Z. Tel, A.U. Sagymbaev, A.D. Sokolov, Z.S. Abisheva, G.A. Zhetpisbaev, S.N.Suleymenov, R.A. Grachev, D.F. Akberdiev, G.A. Maulenberdiev, J.O. Zhilbaev, R.D. Gadzhiev, H.A. Daniyarov, Kh.T. Tuleubaeva, D .Z.Torybaeva and others).

To date, research on the scientific works of Kazakhstani scientists defines several scientific areas related to the use of health-saving technologies in the pedagogical process:

- the first direction concerns certain aspects of the problem of creating health care and maintaining a healthy lifestyle (HLS) of holistic pedagogical process subjects, which are highlighted in the works of scientists: S.N. Suleimenova, D.F. Akberdieva, G.A. Maulenberdieva, J.O. Zhilbaeva, R.D. Gadzhiev, D.Z.Torybaeva, I.I. Petrenko. -the second direction is associated with the use of health-saving and health-forming technologies in the educational process of secondary and higher schools (A.E. Abylkasymova, K.A. Daniyarova, Kh.T. Tuleubaeva and others).

An analysis of the scientific literature on the research problem showed that despite a significant number of pedagogical studies of valeological education of students, the ways and mechanisms of studying the features of the application of progressive health-saving technologies in the process of teaching students in general and in the process of improving their mental activity in particular remain unsolved.

\section{RESULTS AND DISCUSSION}

Mental activity requires not only a trained brain, but also a trained body. There are objective and subjective learning factors that affect the psycho physiological state of students. Objective factors include the living environment and academic work of students, age, gender, state of health, general academic workload, rest, including active. Subjective factors include knowledge, professional abilities, motivation for learning, working capacity, neuro psychic stability, the pace of educational activity, fatigue, psychophysical capabilities, personal qualities (character traits, temperament, sociability), the ability to adapt to the social conditions of study at a university.

All these factors allow us to evaluate only the general patterns of mental work of students. However, it can be assumed that changes in the body that occur under the influence of student work are very insignificant compared with shifts during physical work. The mental activity of students leads to an increase in heart rate during the school day, an increase in the maximum and minimum blood pressure (by 16 and 32\%, respectively), a decrease in body weight, and a slight decrease in the number of leukocytes during the exam period. Some classes lead to an increase, while others lead to a decrease in the excitability of the visual analyzer. Two-phase changes in the excitability of the visual analyzer were noted: an increase - after a low intensity and a decrease - after a high intensity mental activity (S. D. Khoruzhaya).

In some cases, an increase in excitability is combined with a violation of the dynamics of excitatory and inhibitory processes, and in other cases, a violation of the dynamics of these processes is accompanied by a decrease in excitability (E.K. Redkina, E.A. Shirokova). Significant changes are observed in the EEG (Yu. M. Pratusevich). Discrepancies in the shifts in the first and second signal systems of students after classes were noted: within the first signal system, only a weakening of the processes of internal inhibition is observed, while second-signal connections are inhibited (A. S. Dmitriev).

A student as a person of a certain age and as a person in general can be characterized on three sides. Firstly, with the social, in which social relations are reflected, the inclusion of a young person in the student environment, the fulfillment by him of the functions and duties prescribed by the university process of training and education. Secondly, with the psychological, that is the unity of mental processes, states and personality traits 
(temperament, character, ability, focus). Thirdly, with biological, this includes a type of higher nervous activity. This side is determined by genetic and age-related characteristics, but within certain limits it changes under the influence of living conditions and purposeful upbringing and self-upbringing.

Among the perceptual tasks offered to them by the subjects, a problem was applied, the successful solution of which is aimed at visual or proprioceptive orientation (based on visual or vistibular analyzers). This technique is known as "Core and Frame". The subject was required to establish the vertical position of the luminous rod enclosed in a frame. The orientation of the test subject in space occurs either visually or by the position of the body in space. Perceptual features were associated with that analyzer, which provides reflection at the perceptual level. The first experiments of G. Vitkin using the "Rod and Frame" technique allowed him to detect differences in the subjects in distinguishing the figure and background during perception. It turned out that some people can hardly distinguish the dominant stimulus (figure) from those located on the periphery of the visual field. They are distinguished by the integrity of perception and were called field-dependent others could quickly isolate the figure, isolating it from the surrounding stimuli that make up the background. They were called field independent. The perception of the latter is characterized by analyticity and detail. In this regard, the concepts of "zero differentiation" and "field dissection" appeared. Field-dependent is the bipolar characteristics of the subjects, differentiated by the methods of perception, which served as the basis for the use of the term "psychological differentiation".

Denoting dependence - independence from the field of perception, as a stable characteristic, G. Vitkin later made an attempt to associate personality traits with him, personality tests were used: Rorschach spot test, Thematic apperceptive test (TAT, Thematic apperception test (TAT) ) - a projective psychodiagnostic technique developed in the 1930s at Harvard by Henry Murray and Christiana Morgan), and tests of free associations and others [8, p.138-141]. We used these techniques when conducting experimental work on the research topic as well.

All of the above testifies to the general laws of mental work and those psychological factors that affect the development and improvement of the student's mental activity. At the initial stage of the study, we carried out work to identify the real state of the formation of mental activity of students through health-saving learning technologies. We made this determination based on the application of empirical methods of questioning students, talking with them, in the process of observation.

To determine the effective methods for determining the psychological and pedagogical influence of health-saving educational technologies on improving the mental activity of students and identifying the real state of the problem under study, we conducted a stating experiment. The experiment was attended by 186 students of 1- 4 year of pedagogical specialties, aged 17-20 years, and 32 teachers of M. Auezov South Kazakhstan State University and Korkyt Ata Kyzylorda State University.

It is noted that in the framework of the study in the experiment, the following educational activities were organized:

- diagnostic - monitoring of indicators of health and development of students;

- didactic - through the organization of a system of classes using health-saving technologies;

- corrective and improving procedures - charging for the eyes, herbal medicine, aromatherapy, etc ;

- prophylactic - they help optimize students' motor activity, prevent physical inactivity and hypokinesia, and at the same time carry a psychological and pedagogical load, streamline, make active students rest on breaks, which also contributes to the formation of health-saving learning technologies; 
- consultative - the organization of continuing education courses for teachers on the development of mental activity of students through health-saving teaching technologies [9].

In this article, we introduce the results of student surveys. The results of student surveys to identify the importance of health-saving technology are presented in Table 1.

Table 1. Student Survey Results.

\begin{tabular}{|c|c|c|}
\hline Questions & Students' answers & Number of students \\
\hline \multirow{3}{*}{$\begin{array}{l}\text { What do you think "health- } \\
\text { saving technologies" } \\
\text { mean? }\end{array}$} & It's necessary to do sports & 70 \\
\hline & It's necessary to be tempered & 67 \\
\hline & eat fruits, vegetables & 71 \\
\hline \multirow{3}{*}{$\begin{array}{l}\text { Lists the illnesses that often } \\
\text { bother you }\end{array}$} & Nothing bothers & 160 \\
\hline & $\begin{array}{l}\text { constantly sick (various diseases, } \\
\text { ranging from mild colds to serious } \\
\text { complications) } \\
\text { cold }\end{array}$ & 65 \\
\hline & cold & 100 \\
\hline \multirow{3}{*}{$\begin{array}{l}\text { Do you often miss classes } \\
\text { due to illness? }\end{array}$} & no absences & 183 \\
\hline & absences every month & 125 \\
\hline & absences every week & 17 \\
\hline \multirow{3}{*}{$\begin{array}{l}\text { Do you do physical } \\
\text { exercises in the morning? }\end{array}$} & no & 65 \\
\hline & yes & 189 \\
\hline & sometimes & 71 \\
\hline \multirow{3}{*}{$\begin{array}{l}\text { How do you do exercises in } \\
\text { physical education classes? }\end{array}$} & with full dedication & 221 \\
\hline & «not to scold other people» & 70 \\
\hline & without desire & 34 \\
\hline \multirow[t]{4}{*}{ Do you do sports? } & At sports school & 85 \\
\hline & In other institutions & 79 \\
\hline & at the sports section & 90 \\
\hline & nowhere & 71 \\
\hline \multirow{3}{*}{$\begin{array}{l}\text { Do you feel tired after } \\
\text { class? }\end{array}$} & Very tired & 29 \\
\hline & always & 11 \\
\hline & never & 203 \\
\hline
\end{tabular}

After analyzing the results, we can draw the following conclusions. Students have identified the concept of "health-saving learning technology" (hereinafter referred to as "HST") with the concept of "health", with 63 students considering HST as "when nothing hurts you," on the other hand, they do not provide for any actions aimed at strengthening and maintaining health, this suggests that they misunderstand what is included in the content of the concept of "HST". The same can be said of 54 students who believe that HST is "you need to be healthy." But 208 students have elementary ideas about HST, they call some of the components of HST - "you need to play sports, eat healthy foods, fruits, vegetables, temper", but so far their knowledge has not yet been systematized and fragmented.

Students have a positive attitude towards physical education classes, 221 students go in for sports "with full dedication," in addition, 254 students go to various clubs and sports sections (dances, tennis).

Consequently, most students are inclined to adhere to the leading principles of HST, but they do not always implement consistently and continuously, since only 189 students do 
exercises every morning, and 71 only occasionally, and 65 students do not do exercises at all. This suggests that a minority of respondents has a focus on self-improvement.

When talking with students about the state of students' posture, we got the following results: $58.58 \%$ try to sit at a desk or sometimes a desk, sometimes $7.85 \%, 33.57 \%$ do not try to take the right position, which is a large percentage and indicates a high degree of risk of curvature of the spine.

The state of vision is also alarming. $93.58 \%$ see well that they write on the blackboard from their place in the classroom, and $6.42 \%$ do not see well what the teacher writes on the blackboard. This indicator may also include students with low vision, with an incorrectly occupied place in the classroom, etc.

To the question: "What will you do if you feel unwell?" $82.14 \%$ of respondents address to parents for help right away, the rest of the students say to parents only when they become very ill, or wait for the parents to notice the poor health of the child.

When we asked about the dangers of smoking, students answered that smoking was dangerous for health $89.28 \%, 3.58 \%$ do not know whether smoking is harmful or not, and $7.14 \%$ absolutely answered that they did not consider smoking dangerous for health, but $82.85 \%$ believe that smoking significantly reduces life. In the choice of the object most exposed to the harmful effects of smoking, students indicated: girls - $17.14 \%$; boys $-1.42 \%$; both sexes - 52.86\%, "adults" - 5.00\%, "all" - 23.58\%.

Most students are correctly oriented in this matter and have an idea about the dangers of smoking.

To the question "Is alcohol harmful to the body?" $82.14 \%$ of respondents answered positively: "Harmful, regardless of the amount consumed." 5\% disagree with them, and $12.86 \%$ do not know the answer to the question.

According to our research, we can conclude: those students who parents and teachers carried out certain work with, at their possible level, knowledge, abilities and skills of a healthy lifestyle have a tendency to a fairly deep analysis, they are more observant, accurate in definitions, and as the main values called time and health [10, p. 161].

According to the results of the following questionnaire (table 2), we found that the indicators of the activity component are expressed rather weakly. Analyzing the students' answers, we determined that the students have the least developed skills for independent hardening procedures (only 40 students noted that they use hardening in daily forms of activity, 211 gave a negative answer, which is most likely due to the lack of necessary knowledge about methods and techniques of hardening).

We also noted that students are not familiar with the rules of organizing academic work at home (only 54 students pay attention to this aspect of general educational services, 185 students noted that they did not take any measures to organize their educational activities at home). This suggests that many students take for granted poor lighting of the workplace, do not pay attention to signs of fatigue, posture, which will undoubtedly affect their health in the future [11, pp. 102-107].

Many students (182) during the questionnaire noted that they do not fully understand the importance of methods of self-regulation of their mental state (for example, relieve nervous tension by physical education, music, sleep, communication with animals and nature, etc.). This aspect of a healthy lifestyle is very important for ensuring harmony and comfort of mental and emotional state, as nervous overload increases as one grows up, and a person instinctively searches for ways to relax, to be distracted from life problems, stresses, which very often leads to addiction to alcohol, cigarettes and drugs.

If you build confidence among students that they can control their emotions, teach them methods and techniques of self-regulation, self-control, then this will help them subsequently avoid becoming acquainted with bad habits, and this aspect of HST should be included in the content component of the organization of extracurricular activities students. 
Table 2. The results of the questionnaire to identify the presence in students of the skills of selforganization of a healthy lifestyle.

\begin{tabular}{|l|c|c|c|}
\hline Mark the one that you can do yourself to maintain your & \multicolumn{3}{|c|}{ Answer Options } \\
\cline { 2 - 4 } own health & yes & no & $\begin{array}{c}\text { I find it } \\
\text { difficult to } \\
\text { answer }\end{array}$ \\
\hline 1. Create for yourself a complex of morning exercises; & 90 & 105 & 130 \\
\hline 2. To organize a mobile or sports game with peers & 128 & 85 & 112 \\
\hline 3. Compose and observe the correct daily routine; & 122 & 104 & 99 \\
\hline 4. Perform hardening procedures (water, air, solar) & 40 & 211 & 74 \\
\hline $\begin{array}{l}\text { 5. Relieve nervous tension (physical education, music, } \\
\text { sleep, communication with animals and nature, etc.) }\end{array}$ & 70 & 73 & 182 \\
\hline $\begin{array}{l}\text { 6. Organize homework (physical break, good lighting, } \\
\text { etc.) }\end{array}$ & 54 & 185 & 86 \\
\hline
\end{tabular}

Summarizing the data obtained in the course of identifying the degree of formation of indicators, we found that students have rather poorly formed skills of self-organization of HST, which, in our opinion, is most directly related to the lack of proper motivation. Students in the learning process, unfortunately, often lose their health, experiencing overloads intellectual, physical and mental. Often they are in a state of anxiety, which also negatively affects the health of students.

The materials obtained clearly indicate the need to implement health-saving teaching technologies in the educational process of the university, to educate students in the need for health and to form adequate representations of the nature of the health care system.

\section{CONCLUSION}

Health-saving technologies should be considered as an integral part of the educational system and everything related to education - methods and techniques of training and education, the level of professional culture of teachers, the conditions of the educational process, etc. everything is directly related to the health of students $[12$, p. 86].

Today, the issue of the health status of student youth is very acute - the present and future intellectual and labor potential of our country. The system of higher professional education is closely related to health - the effectiveness of education and upbringing in higher education is largely determined by the level of health of students, and the quality of education cannot be considered outside the context of labor costs and the health of subjects of the educational process. The goals and objectives to be solved in education cannot but be commensurate with the psychological, pedagogical and physiological laws of educational and labor activity, the psychophysical capabilities of students; without this, the goals of education in many ways lose their social and personal significance.

\section{References}

1. Message of the Head of State N. Nazarbayev to the people of the Republic of Kazakhstan "Development Strategy of the Republic of Kazakhstan until 2050.", Astana, (2012)

2. The state program of health development of the Republic of Kazakhstan "Healthy Kazakhstan", Collection of acts, 25-26 2010) 
3. The Law of the Republic of Kazakhstan "On the Protection of Citizens' Health", Bulletin of the Parliament of the Republic of Kazakhstan, 14 (2471), 106-127 (2006)

4. Zh. Z. Torybaeva, Collection of articles of the 4th International Conference of Young Scientists "Actual problems of modern science", 138-141 (2003)

5. Zh. Z. Torybaeva, Methodology for the formation of a healthy lifestyle of students in the process of joint work of the university, family and the public: Textbook, 108 (M. Auezov SKSU, Shymkent, 2004)

6. E. D. Dalenov, V. B. Khasin, N. V. Slivkina, L. Zh. Ismagambetova, G. S. Syzdykova, Health and disease, 4 (60), 19-24 (2007)

7. A.M. Uteshkalieva, Pedagogical conditions for the formation of a healthy lifestyle of younger students, 171 (Atyrau, 2006)

8. G. I. Kuznetsova, V. L. Kharchenko, Psychology Issues, 6, 138-144 (1981)

9. Zh. Saparkysy, International Journal of Environmental and Science Education (Turkey), 11 (18), 12235-12244 (2016)

10. Zh. Saparkyzy, Collection int. conf. Europen scientific conference, 157-161 (2018)

11. Sh. M. Maygeldieva, Zh. Saparkyzy, Bulletin of the Kazakh National Pedagogical University named after Abay, 1 (58), 102-107 (2019)

12. Zh. Saparkyzy, Sh. Maygeldieva, A. Ayaganova, L. S. Koldasova, Bulletin of the Kazakh National Pedagogical University named after Abay, 1 (60), 86-91 (2019)

13. A. E. Abylkasymova, Formation of cognitive independence of students of preparatory departments in the process of studying a course of mathematics, (Almaty, 1991)

14. T. V. Minakova, The development of cognitive independence of university students in the process of learning a foreign language (Orenburg, GOU OGU, 2008)

15. A. V. Kiryakova, Theory of personality orientation in the world of values, 188 (Publishing House of the OGPI, 1996) 